\title{
Las metáforas antropomórficas, zoonímicas y vegetales: ejes de la cultura de los valles de los ríos Sinú y San Jorge*
}

\section{Anthropomorphic, animal and plant metaphors: axes of the culture of valleys of Sinú and San Jorge rivers}

Ernesto Llerena García**

\section{Resumen}

El artículo presenta la manera como el cuerpo humano, los animales y los vegetales son fuentes importantes en la construcción metafórica de elementos léxicos y expresiones dentro de una cultura, en particular la de las comunidades de los valles de los ríos Sinú y San Jorge en el departamento de Córdoba, Colombia. De manera general, se presentan los esquemas metafóricos fundamentales utilizados en estas construcciones y los resultados obtenidos a partir de un corpus de dos mil (2000) unidades léxicas.

Palabras clave: metáfora, lingüística cognitiva, esquema mental, cuerpo humano, animales, vegetales.

\begin{abstract}
This article presents the way how human body, animals and plants are important sources in metaphorical construction of lexical items and expressions within a culture, in particular those communities of the valleys of Sinú and San Jorge rivers in the department of Cordoba, Colombia. Generally, it is presented the basic metaphorical schemes used in these constructions and the results obtained from a corpus of two thousand (2000) lexical units.
\end{abstract}

Keywords: metaphor, cognitive linguistics, mental schema, human body, animals, plants.

\footnotetext{
* El presente artículo hace parte de la tesis sobre Diccionario etnolingüístico de los valles de los ríos Sinú y San Jorge, del Doctorado en Lingüística de la Universidad de Antioquia.

** Profesional en idiomas, Magister en etnolingüística, Candidato a Doctor en Lingüística, Universidad de Antioquia.
} 


\section{Las metáforas en la lingüística cognitiva}

La metáfora cognitiva tiene sus orígenes en la lingüística cognitiva, disciplina que tiene como fundadores a George Lakoff y Mark Johnson (1995), quienes provenían de la semántica generativa. La teoría de Lakoff y Johnson pretende corregir el excesivo desvío hacia la sintaxis originado por el formalismo reglado de la teoría formal de Chomsky. Lakoff ensanchó las fronteras del lenguaje creando una perspectiva interdisciplinar a la que denominó Lingüística Cognitiva y en la que el lenguaje se relaciona con otros aspectos perceptivos y cognitivos como la memoria, la atención e incluso la neurología o la inteligencia artificial. Lakoff prosigue el camino iniciado en la semántica generativa y considera que la importancia del significado deriva de que, a diferencia de la forma sintáctica, no tiene un carácter compositivo y de que en él confluyen varias disciplinas (Crespillo, 2011, p. 1).

El punto de partida es un modelo perceptivo fundado en el uso experiencial. Con posterioridad a Ullmann (1962) y antes de Lakoff y Johnson (1980), se publicaron algunas obras en las que se empezó a relacionar la metáfora con la cognición y no solo con la literatura y el cambio de significado. Esto puede apreciarse en el libro de la década del 70: The Poetics of Growth: Figurative Language in Psychology, Psychotherapy and Education publicado en 1977 por H. Pollio, M. Barlow H. Fine y M. Pollio. En esta obra los autores trataron de demostrar que la metáfora es un proceso mental recurrente a la par que propio del comportamiento humano (Julia, 2010, p. 95).

Lakoff y Johnson se han interesado en explicar, por un lado, la metáfora como un mecanismo para aprehender la realidad y, por el otro, la naturaleza de los sistemas conceptuales. Para los autores, la metáfora nos permite estructurar conceptos a partir de otros. La forma en que realizamos este proceso depende de nuestras experiencias directas con el mundo a través de nuestro cuerpo. Por lo tanto, las metáforas impregnan el lenguaje cotidiano formando una red compleja e interrelacionada tanto para las nuevas metáforas como para las consideradas ya formadas.

Las experiencias cotidianas a las que se enfrenta el hablante y su forma de relacionarse con el mundo le permiten crear esquemas mentales para organizar su 
realidad; también le permiten establecer asociaciones con situaciones corporales nuevas. Para Lakoff y Johnson (1995, p. 39), el hablante establece una serie de relaciones entre aquellas situaciones concretas o fáciles de entender con las más complejas y abstractas; y en este proceso se van creando una serie de relaciones y de conceptos nuevos.

Constantemente, los hablantes emplean una serie de metáforas como un mecanismo de aprehender situaciones complejas. Los hablantes crean un sistema conceptual basado en su relación con el ambiente y con su cultura, y esa experiencia cotidiana fija, a través de metáforas, la realidad; pero también puede proporcionar, mediante metáforas imaginativas y creativas, nuevas formas de comprender la existencia. Las metáforas nos hablan de nuestro entorno, de los valores y de los antivalores de la sociedad.

Las metáforas tienen implicaciones por medio de las cuales destacan y hacen coherentes ciertos aspectos de nuestra experiencia. Una metáfora determinada puede ser la única forma de destacar y organizar de forma coherente precisamente esos aspectos de nuestra experiencia. De igual manera, Las metáforas pueden crear realidades sociales.

Lakoff y Johnson (1995, p. 50) explican que el hablante ha identificado, a través de su experiencia física y cultural, que arriba es positivo y abajo es negativo, de ahí surgen expresiones metafóricas como se me levantó la moral para transmitir un estado de bienestar o satisfacción o mi moral cayó por los suelos para indicar tristeza. Los investigadores han encontrado que los hablantes establecen comparaciones entre las sensaciones corporales y otras situaciones que sugieren bienestar, como la virtud, la salud y la fuerza, con estar arriba; y situaciones asociadas al malestar, como la enfermedad, el vicio y el control, con abajo (Lakoff y Johnson 1995, p. 51-53). Estos autores afirman que los hablantes poseen una serie de esquemas mentales abstractos llamados mapping (metáfora conceptual) y que gracias al conocimiento de las metáforas conceptuales subyacentes o mapping se construyen las expresiones metafóricas: el significado figurado de estas unidades está motivado por el conocimiento tácito de los hablantes de las metáforas conceptuales subyacentes.

\section{Las metáforas en las comunidades de los valles de los ríos Sinú y San Jorge}


Las metáforas surgen a partir de la experiencia que tienen las personas de una comunidad según las relaciones que establezcan con el mundo animal, mundo vegetal, el mundo humano y los objetos del lugar donde habiten. Las personas, a través de la interacción y la observación de las formas de vida del mundo animal y vegetal, pueden determinar características fundamentales sobre aspectos físicos y comportamentales tanto en su hábitat como en los lugares que comparten con otros humanos.

A partir de estas observaciones el hablante construye una serie de producciones lingüísticas comparativas entre la forma de vivir, alimentarse y actuar de los animales y plantas, con el de las personas. Estas construcciones léxicas son precisamente las que denominamos metáforas antropomórficas, zoonímicas y vegetales. Como lo plantea Kekié (2008, citado por Jiménez, 2013, p. 207), estas metáforas son aquellas alusiones metafóricas o alegóricas humanas, de animales y plantas, para referirse a una conducta o a una característica del hombre, de una planta o de un animal.

Nuestra forma de relacionarnos con el entorno, la experiencia directa, corporal, psicomotriz, nos ayuda a comprender, a través de las metáforas, otras realidades más abstractas y lejanas que no se podrían entender a simple vista (Lakoff, 1995). Toda esa experiencia cotidiana está impregnada de la cultura popular y, según Kekié (2008, citado por Jiménez, 2013, p. 207, 208), queda plasmada en las unidades fraseológicas de la lengua. De acuerdo con lo anterior, tenemos dos formas de acercarnos al análisis de la metáfora: por un lado, está la que nos habla de la manera en que nos acercamos a la realidad $\mathrm{y}$, por el otro, el aspecto cultural que determina cómo percibimos los acontecimientos de la vida cotidiana. Kekié (2000, p. 110-111) establece tres tipos de motivación semántica en las unidades fraseológicas metaforizadas:

1. Motivación icónica o metáfora conceptual, que surge de mecanismos universales: reposa sobre los conocimientos que tenemos del mundo y es directamente deducible de la percepción y la experiencia. El modelo descriptivo sería: experiencia - modelo icónico - archimetáfora -metáfora particular.

2. Motivación simbólica o metáfora cultural, donde es el símbolo cultural lo que motiva una expresión: se basa en conocimientos culturales, convencionales, costumbres, mediados por las creencias colectivas y el aprendizaje. El modelo 
descriptivo sería: trasfondocultural - culturema (entendido como símbolo + simbolizado) -metáfora particular.

3. Motivación metafórica o metáfora en cadena o metalingüística: la fuente de una metáfora no solo puede ser una experiencia directa, o un símbolo preexistente, sino también otra metáfora.

Para esta investigación el fundamento es la motivación icónica o metáfora conceptual y en la motivación simbólica o metáfora cultural, esto es, experiencia de vida; por lo tanto, pueden variar de una comunidad a otra. Así por ejemplo, en la fraseología zoonímica estudiada por Kekié, se encuentra que un animal como el gato, que tiene atributos como la astucia y refiere a situaciones difíciles e incómodas, en otras lenguas, como el serbio, representa la lujuria, la hostilidad, la crueldad, la traición y el desprecio. De igual manera, en muchas culturas la vaca simboliza la fertilidad, el amor materno, la alimentación; la mula, el silencio; sin embargo, en otras culturas estos animales representan la vagancia y la estupidez. Es importante señalar que estos atributos van cambiando a través del tiempo; el gato, por ejemplo, en Costa Rica, según Kekié, hoy ya no es registrado como complicación sino más bien como la agilidad y la astucia. De ahí que podamos distinguir metáforas que son legitimadas como tales y, por lo tanto, podrían encontrarse en otras lenguas, y metáforas que responden a situaciones muy locales y que están relacionadas con situaciones culturales particulares como las tradiciones.

Así, de aquellas metáforas que se encuentran en otras lenguas se pueden destacar las de aquellos animales que nos hablan de la fidelidad, como el perro, de la estupidez, como el burro, de la laboriosidad, como la hormiga y la abeja o del hablar mucho, como el loro parlanchín.

Sobre las metáforas, concluimos, tal y como lo hace Kekié (2000, p. 127), que estas metáforas se originaron a partir de la observación directa o sobre un conocimiento subjetivo sobre un animal, una planta o sobre el propio cuerpo que luego se transmitió como un valor simbólico de una cultura común. Siguiendo a Lakoff y Johnson (1995, p.55), la producción metafórica se basa en la percepción, las facultades psicomotrices y la experiencia "corporeizada". A partir de estos conocimientos, proyectamos vivencias y ordenamos lo que vemos, escuchamos o sentimos de acuerdo con estos patrones mentales. En este sentido, cuando decimos que una persona se parece a un animal o que 
los animales están presentes en nuestra cotidianidad, partimos de un esquema abstracto que, tal como vimos anteriormente, se denomina metáfora conceptual y de ella se originan una serie de expresiones metafóricas o metáforas particulares.

Con el fin de ordenar el proceso cognitivo, Iñesta y Pamies (2002, citado por Jiménez, 2013, p. 206) propone cuatro niveles: el dominio meta, los dominios fuente o modelos icónicos, las archimetáforas y las metáforas particulares. Los dominios meta pueden ser sensaciones (miedo, rabia, alegría, etc.) o referente a uno de los tres campos semánticos: el ser humano, el mundo animal y el vegetal. Los dominios fuente son el ser humano, el mundo animal y el mundo vegetal. Para el análisis de las metáforas en este estudio, se proponen los siguientes niveles:

1. Dominios fuente y meta: SER HUMANO ${ }^{1}, \mathrm{ANIMAL}^{2}$, VEGETAL ${ }^{3}$, OBJETOS, ESPACIOS, UNIDAD DE MEDIDA.

2. Archimetáforas:

\subsection{El ser humano es un animal}

2.1.1. Una parte del cuerpo humano es un animal o una parte de un animal

2.1.2. Un estado de ánimo humano es un animal

2.1.3. Una cualidad humana positiva es un animal

2.1.4. Una cualidad humana negativa es un animal

2.1.5. Un comportamiento humano es un animal

2.1.6. El mundo humano (cuerpo humano, oficios, nombres propios, familia, características humanas) es transferido al mundo animal

2.2. El ser humano es un vegetal

2.3. Una parte del cuerpo humano es otra parte del cuerpo humano

\footnotetext{
${ }^{1}$ En los valles de los ríos Sinú y San Jorge se encuentran gran cantidad de topónimos creados a partir del cuerpo humano y producciones corporales: Cuatro Bocas, Boca de Tinajones, Boca de la Ceiba, Jopo, Mojón Rodao.

${ }^{2}$ En los valles de los ríos Sinú y San Jorge se encuentran gran cantidad de topónimos creados a partir de nombres de animales: Las Iguanas, Cotorra, Rabo Largo, Las Palomas, Canta Rana, Morrocoy, El Tigre, El Águila, Los Pericos, La Gallera, Burro Muerto, Pasa Caballo, Garzones, El Bagre, El Mico, Las Babillas, Los Venados, El León, Pueblo Pescao, Mico, La Sapera.

${ }^{3}$ En los valles de los ríos Sinú y San Jorge se encuentran un gran número de topónimos creados a partir de nombres de plantas o frutos: El Ñipi, Miraflores, El corozal, el Níspero, La Ceiba, Puerto Platanito, Las Cañas, La Palma, Los Robles, La Madera, El Palmar, Florisanto, Los Laureles, Tres Palmas, La Coroza, El Limonar, Papoche, El Ceibal, Los Cedros, Guayabal, El Campano, El Varal, Los Limones, El Manguito, El Tomate, Palotal, El Corozo, Mata de Caña, Rosa Vieja, la Flor, El Higal, Corozalito, Las Guamas, La Palma, Los Cocos, Los Manguitos, El Ébano, Palma y Vino, Cadillo, Mata de Plátano, El Limonal, El Ají, Corozal, El Níspero.
} 
2.4. Una parte del cuerpo humano o una cualidad humana es un objeto

2.5. El ser humano es una enfermedad

2.6. Un animal o una parte de un animal es otro animal

2.7. Un animal es un vegetal

2.8. Un animal es un objeto

2.9. Un animal es un elemento terrestre

2.10. Metáforas de animales transferidos a los alimentos

2.11. Un vegetal es una parte del cuerpo humano

2.12. Un vegetal es un animal

2.13. Un vegetal es una parte de un animal

2.14. Un vegetal es otro vegetal

2.15. Un vegetal es un elemento terrestre

2.16. Un vegetal es un alimento

2.17. Una producción de un vegetal es una producción del cuerpo humano

2.18. Un objeto es una parte del cuerpo humano

2.19. Un objeto es una parte del cuerpo de un animal

2.20. Un objeto es una unidad de medida

2.21. Un espacio es una parte del cuerpo humano

2.22. Una cualidad inherente es un animal o un vegetal

2.23. Una parte del cuerpo humano es una unidad de medida

2.24. Un alimento es una unidad de medida

2.25. Metáforas sinestésicas

2.26. Metáforas de lo concreto a lo abstracto

El objetivo de esta clasificación, siguiendo a Pamies (2002), es conformar un numeroso inventario de metáforas que se desprendan de una idea común llamada modelo icónico; este modelo conformado por dominios debe corresponder a nociones universales o razonablemente susceptibles de serlo y debe incluir muchas metáforas particulares, por lo que se hace necesario contar con un nivel como el de las archimetáforas para clasificar cada grupo de alusiones metafóricas de acuerdo con las características de cada grupo. A continuación se analizan cada uno de los veintiséis modelos icónicos propuestos. 
Se ha encontrado una gran cantidad de términos y expresiones metafóricas (269) en la presente investigación, en especial, aquellas relacionadas con el cuerpo humano, los animales y las plantas. Siguiendo a Ullmann (1965), Pamies (2002), Julià (2010) se pueden dividir los tipos de metáfora encontrados en los valles de los ríos Sinú y San Jorge de la siguiente manera:

\section{Archimetáfora 1: El ser humano es un animal}

Se encontró una gran cantidad de imágenes de animales transferidas a la esfera humana (24) (con frecuencia adquieren connotaciones humorísticas, irónicas, peyorativas o incluso grotescas). Un ser humano puede ser comparado con una inagotable variedad de animales: un perro, un gato, un cerdo un burro (Ullmann, 1965, p. 242). Según Echevarría (2003), una de las principales metáforas del español es las personas son animales, esto por cuanto proyecta conceptos de un dominio origen (animal) a un dominio distinto (ser humano). Según este modelo, las personas pueden ser muchos animales. Cuando a una persona se le dice que parece un animal se está estableciendo una comparación con la totalidad del animal, como los siguientes términos relacionados con personas de las comunidades de los valles de los ríos Sinú y San Jorge: ñeque "persona ágil”, pulga "persona que se mueve mucho".

Se crean también expresiones (5) como: el que se escama es porque es pescado "persona que se exaspera sin que lo involucren directamente", tener los ojos ni chivo ahorcado "tener los ojos muy tristes", tener cara de burro montando un planchón "estar alguien asustado", metemono "persona que le gusta aparentar".

A partir del dominio fuente animal se puede llegar a otro dominio (meta), según la virtud o característica que se quiera resaltar: una parte del cuerpo humano es un animal o una parte de un animal, un estado de ánimo humano es un animal, una cualidad humana positiva es un animal, una cualidad humana negativa es un animal, el comportamiento humano es similar al de un animal y las actividades cotidianas humanas son actividades zoonímicas.

a) Una parte del cuerpo humano es un animal o una parte de un animal: $\mathrm{Se}$ puede nombrar un animal o una parte del cuerpo de un animal para referirse a una parte 
el cuerpo humano. Es bastante productivo el símil "parte del cuerpo+ e (de) +animal" (proceso de formación lexicogénico de carácter sintáctico por determinación) para este tipo de metáforas de animales transferidas a la esfera humana (19): cara de bagre "persona que es muy fea", oreja de mulo "persona que tiene las orejas pequeñas", nariz de guasale "persona que tiene la nariz grande", oreja de perro "persona que tiene las orejas pequeñas", nariz de simio "persona que tiene las nariz ancha", ojo de cocinera 4 "persona que tiene los ojos grandes", culo de gallo "persona que tiene las nalgas paradas", oreja de puerco "persona que tiene las orejas muy pequeñas", culo de sapo "persona que tiene las nalgas planas", carita de ratón "persona que tiene la cara de forma puntiaguda", pata de perro "persona que no se mantiene en la casa", nariz de tacan "persona que posee una nariz muy pequeña", ojo de vaca "persona que tiene ojos muy grandes", nariz de puerco "persona que posee los hoyos de la nariz muy grandes", nariz de loro "persona que posee la nariz muy puntuda", diente de vampiro "persona que posee los dientes muy largos", diente de ratón "persona que posee dientes muy grandes y separados", culo de avispa "persona que tiene los glúteos muy parados", pata de panela "persona que tiene las piernas curvas", nariz de guazalé "tener la nariz grande", culo de pato "tener las nalgas grandes", pelo de zorra "mujer de cabello desordenado".

b) Un estado de ánimo humano es un animal: Se encuentran estados de ánimo de los seres humanos relacionados con los de los animales (2): perro apaliao "persona que se siente deprimida", sentirse como un toro "sentirse con mucha fuerza".

c) Una cualidad humana positiva es un animal: Existen animales que destacan (desde el punto de vista humano) por su capacidad para el trabajo, la valentía, su buen carácter o su agilidad (4): gallo "persona buena peleadora", abeja "persona atenta y dispuesta a aprovechar las oportunidades que se le presenten en la vida", avispa "persona viva y ágil", hormiga "persona activa y trabajadora".

Con este tipo de términos se construyen también refranes (3) en las comunidades de los valles de los ríos Sinú y San Jorge: a cada pajarito le gusta su nidito; la vaca parida no come lejos porque el ternero está bramando; cada asno, con su tamaño.

\footnotetext{
${ }^{4}$ La cocinera es un ave.

${ }^{5} \mathrm{El}$ guasalé es un ave
} 
Asimismo, existe la estructura "más+cualidad positiva +que un + animal" para este tipo de metáfora: más manso que una paloma.

d) Una cualidad humana negativa es un animal: Las metáforas que tienen connotaciones negativas (41) se refieren a cualidades como la lentitud, la pequeñez, la cobardía, la terquedad, la locuacidad, la inquietud, la agresividad, etc.: zorra "mujer promiscua", perro "hombre promiscuo, desgraciado", tigre "persona agresiva", culebra "persona a quien se le debe dinero o mujer celosa", gallina "persona miedosa", gallo "persona peleadora", sapo "persona chismosa", anaconda "mujer intolerante, celosa y posesiva que molesta por todo a su marido", bagre "mujer poco atractiva", marrano "persona mal aseada", loba "prostituta", pavo "persona distraída", mosca "persona fastidiosa", burro "persona ignorante", zángano "persona aprovechada", puerca "persona desordenada y poco aseada", anaconda "mujer intolerante, celosa y posesiva que molesta por todo a su marido", tigre "persona agresiva", gallina "persona miedosa", gallo "persona peleadora", sapo "persona chismosa", abeja "persona atenta y dispuesta a aprovechar las oportunidades que se le presenten en la vida", avispa "persona viva y ágil", pavo "distraído", golero "persona que come mucho", morrocoy "persona muy lenta", babilla "mujer muy fea", mico "persona que pasa montado en todos los árboles", caballo "mujer muy grande", puerca "persona muy glotona", novillón "mujer muy grande", pájaro "persona que está en todas partes", culebra " persona que se mueve mucho, es muy rabiosa o a la que se le adeuda dinero".

Se encuentran también refranes (7) relacionados con este tipo de metáfora: $E l$ burro no es tan bestia como piensa el que lo piensa: no siempre se puede juzgar a los demás por su simple apariencia, ya que le pueden sobrar cualidades; quien con burros anda al año rebuzna: enseña que al cabo de un determinado tiempo de andar con alguien se adquieren ciertos hábitos de la otra persona, ya sean estos malos o buenos; aquella gallina no es buena, que come en la casa y pone en la ajena: es criticado la mala conducta que una persona tiene con los de su misma familia y con los demás es alguien totalmente distinto; como gallina vieja: ni pone huevo, ni deja la culequera; se utiliza para aquellas personas que ni viven bien ni dejan vivir bien a los demás; la vaca parida no come lejos porque el ternero está bramando: advierte que las mujeres recién dan a luz permanecen en sus casas cuidando los hijos; perro que no conozcas no le cojas el rabo: advierte que se debe tener cuidado de aquellas situaciones en las que no se tiene experiencia. 
De igual manera, existe la estructura "más+cualidad negativa +que un + animal" para este tipo de metáfora (3): más peligroso que una culebra mapaná, más lento que una tortuga, más rabioso que toro en corraleja.

Las experiencias humanas con partes de animales a través de la interacción con estos crean sensaciones positivas o negativas (1): ser hueso "situación dura o difícil".

e) Un comportamiento humano es un animal: Se encuentra en el corpus de los refranes, aquellos que aluden a comportamientos de animales como si fueran comportamientos humanos (2): Pájaro viejo no entra en jaula: la experiencia es la mejor consejera del ser humano; quien da pan a perro ajeno, pierde pan y pierde perro: advierte que por lo regular quien ayuda a los demás, cuando éste la necesita nunca es ayudado.

Se tiene la estructura "más+ comportamiento humano +que un + animal" para este tipo de metáforas (1): más contento que perro con dos colas.

f) El mundo humano (oficios, nombres propios, familia, características humanas) es transferido al mundo animal (25): los oficios, los nombres de personas, la familia son fuentes muy importantes para la formación de metáforas al mundo animal: cabeza de vieja "fruto", cocinera "ave", la Laura "ave", capitana "arbusto" matandrea "arbusto", María Mulata "ave", María Antonieta "garza", boquita negra "pez", mala madre "arbusto", angelita "planta", tapaculo "árbol”, sonrisa de gaitas " flor", ruye copa “pez”, capitanejo “pez”, viejita “pez”, lambada "pez”, cuatro ojos “pez”, pipón “pez”, cascona “pez”, negrito mata caimán “pez”, señorita “pez”, mamaburra “pez”, curita "ave", monjita "pájaro", nueve hermanas "rosa".

\section{Archimetáfora 2. El ser humano es un vegetal}

No es tan productivo como la de los animales. Se encontraron los términos (18): ser tronco "no tener mucha agilidad", estar en estado vegetativo "parecer una planta, ya que está en coma y solo tiene activa las funciones vitales", palo de coco "hombre de gran tamaño", palmera "mujer de gran estatura", totumo "persona que tiene la cabeza grande", ñame "persona que tiene la cabeza grande" y "pie”, mango "corazón”, batata "músculos gemelos", coco "cabeza", corocitos "senos pequeños", batatas "corvas", 
mango "corazón", pepita "clítoris", guama "pene", plátano "pene", coco "vagina". Y se encuentran los sintagmas (3): cabeza de totumo "persona que posee la cabeza grande y calva", nariz de patacón "persona que posee la nariz muy pancha", pata de guama "persona que tiene las piernas curvas".

Así mismo, gracias a los esquemas metafóricos, las personas de las comunidades estudiadas crean expresiones (7) como: tener más ojos que una piña, estar más pelao que una pepa de guama chupada por loco, tener más hijos que una mata de papoche, tener la bemba como una concha de caimito, ser más resbaloso que concha de platanito, ser una concha de caimito, fastidiar más que una piña bajo el brazo.

Asimismo, se encontró esta archimetáfora en la fraseología: de un solo golpe no se derriba un roble: las grandes obras del hombre no se hacen ni se terminan al primer intento, todo exige un gran esfuerzo; ajo entero salta del mortero: cita a aquellas personas que tienen una personalidad de discordia, mal humor, arrogantes, antipáticas, etc., y no pueden vivir armoniosamente con los demás; al arbolito desde chiquito: si deseamos esperar buenos resultado en algún proyecto humano debemos poner todo el empeño desde el principio.

Archimetáfora 3. Una parte del cuerpo humano es otra parte del cuerpo humano

Hay pocas apariciones en el corpus (3). Se encontró: boca del estómago "parte superior del estómago", cuello del útero "parte interna del útero", cabeza del pene "glande".

Archimetáfora 4. Una parte del cuerpo humano o una cualidad es un objeto

El cuerpo, sus partes y las cualidades humanas pueden ser caracterizados como un objeto (6): parabólicas "orejas grandes", farolas "ojos", canilla "pantorrilla", casco "cabeza", lengua de trapo "persona que posee una lengua muy larga o persona que le gusta hablar mucho", palillo eléctrico "persona bastante flaca", chapita "persona dientona".

Archimetáfora 5. El ser humano es una enfermedad 
Metáforas de enfermedades transferidas a la esfera humana (3): caspa "persona que fastidia mucho", gonorrea "mala persona", pecueca "mala persona".

Archimetáfora 6. Un animal o una parte de un animal es otro animal

En esta archimetáfora ubicamos las expresiones metafóricas que se construyen con uno o dos sustantivos zoonímicos. Generalmente, los animales deben tener una característica que los identifique de otros de la misma especie.

a) Metáforas de un animal transferidas a otro animal (10): Una gran cantidad de nombres de animales se han creado a partir de nuevas formas de nombrar y diferenciar especies a partir del nombre de otro animal: pejepuerco "pez", puerco "ave", bagre de sapo "pez”, perico "pez", tigre "pez”, perro "pez”, rana toro "tipo de rana que es muy agresiva", torito "insecto", toro "ave", ovejón "insecto".

b) Metáforas de líquidos animales transferidos a otro animal (1): líquidos animales como la sangre se utilizan para nombrar otro animal: sangre toro "ave".

c) Metáforas de partes animales transferidos a otro animal (3): Se pueden encontrar términos de partes de animales en términos referidos a otros animales: picuda “pez”, pico de loro "pez", cojón de toro "avispa".

Archimetáfora 7. Un animal es un vegetal

Es menos frecuente (2). Se encontró el término mazorquita "pez"; este término viene dado por el olor y no por la forma del pez; existe un fruto de una planta para nombrar un pez: totumito "pez".

Archimetáfora 8. Un animal es un objeto.

Muchos objetos de la cotidianidad (13) son utilizados como elementos fuente para la creación de metáforas: cuello de botella "gallos de pelea que en la lengua estándar se denominan chilenos, carecen de plumas en el cuello", bola "gallo de pelea que no posee cola por lo que su forma es redonda", aguja "pez de color plateado con dientes pequeños y que en la lengua estándar se denomina agujeta", siete cuero "pez de color blanco, negro y manchas marrones, su piel es dura, de ahí su nombre", tijereta “ave”, caimán aguja "clase de caimán”, vara de humo "árbol”, corona de cristo "planta 
ornamental", clavos de cristo "planta", cintamochila "planta medicinal", siete balazos "planta", sombrilla "hongo", olleto "árbol grueso".

Archimetáfora 9. Un animal es un elemento terrestre

Elementos terrestres como el agua son nombres de animales (1): agua mala "animal".

Metáfora 10. Metáforas de animales transferidos a los alimentos

Es poco frecuente el uso de este tipo de metáforas (2). Se encontró: burro ñato "plátano machacado", cabeza de gato "plátano machacado".

Archimetáfora 11. Un vegetal es una parte del cuerpo humano

La creación de términos nuevos por la extensión de los nombres de las partes del cuerpo es común entre los comunidades de los valles del Sinú y San Jorge, aunque en menor número para nombrar vegetales o sus partes. Se evidenciaron términos (4) como corazón "parte central de la piña", cabeza de ajo "un ajo", diente de ajo "una parte del ajo", pie "una parte de la planta".

Archimetáfora 12. Un vegetal es un animal

Otra fuente perenne de imágenes es el reino animal. Estas metáforas se mueven en dos direcciones capitales. Algunas de ellas se aplican a plantas y a objetos. Muchas plantas deben su nombre a alguna vaga similitud, a menudo caprichosa o burlesca, con un animal: pata de cabra, pata de gallo, cola de perro etc. (Ullmann, 1965, p. 242). Para el estudio de creación léxica de los nombres dados a las plantas varios autores han realizado estudios amplios, ya que es un tema interesante de investigación. Un gran número de nombres de plantas se crean por el mecanismo de la composición (Buenafuentes, 2007).

Dentro de la gran gama de metáforas relacionadas con las plantas, encontramos la metáfora Un vegetal es un animal o una parte de un animal, la cual se lleva a cabo 
mediante la comparación de una parte del cuerpo de un animal con la forma de la planta o porque la planta ha sido identificada como alimento del animal, por lo que se da una relación de pertenencia. En el corpus hallamos nombres de plantas derivados de nombres referidos a una producción corporal de animales, a partes del cuerpo de animales o a animales (22): miao de perro "planta cuyo olor se asemeja a la orina del perro", corazón de hicotea "planta cuyas hojas tienen la forma del corazón de la hicotea", cola de gato "planta cuyas ramas semejan la cola de un gato", tripa de pollo "planta cuyas ramas semejan los intestinos del pollo", cola de caballo "planta", cresta de gallo "planta", orejita de mulo "planta", pico de gallo "planta", pies de gato "planta", cuerno "planta", mierda de pájaro "planta", patavaca "planta", oreja de burro "planta gruesa con hojas largas y verticales en forma de orejas", cantagallo "árbol frondoso", cucaracha "planta", zorra pata de muchacho "planta", uñagato "planta", bocachica "planta acuática", matarratón "planta", mamón mico "tipo de mamoncillo", tabaco de babilla "planta acuática", pollo "planta de plátano cuando está pequeña".

Todas estas metáforas son producto de analogías que han establecido los hablantes con aparentes similitudes que tiene las plantas con una parte del animal. El hecho de que el cuerpo de los animales, frente al cuerpo de los humanos, sea el concepto fuente con el que más frecuentemente se crean nombres de plantas podría explicarse porque en la categorización del mundo el ser humano se considera más próximo a los animales que a las plantas y, por tanto, considera a las plantas más cercanas a los animales (Berlin, 1973). Por un lado, el mundo animal es más cercano al ser humano que el vegetal debido a las similitudes entre hombre y animal en cuanto a estructura corporal, tanto interna como externa, y en cuanto a alguna de las actividades vitales del quehacer cotidiano de ambas especies de seres vivos (comer, defecar, oler, ver, oír, sentir, correr, etc.); por ello, es más frecuente que las proyecciones metafóricas del cuerpo humano se dirijan a los nombres de animales que a los de las plantas. Por otro lado, es probable que la jerarquía de la división biológica, el hombre considere al mundo animal más cercano al vegetal $\mathrm{y}$, por ello, sea más frecuente hallar denominaciones de plantas formadas con nombres de partes del cuerpo de los animales, como también existen casos de nombres de animales empleados para designar ciertas plantas (araña, dragón, erizo) (Julia, 2010, p. 115). 
De mayor productividad (10), encontramos: cola de caballo "planta", uña de gato "planta", pie de pajarito "planta parásita", oreja de mulo "planta acuática", bola de gato "planta", pata de baca "planta", tabaco de babilla "arbusto", mano de tigre "tipo de plátano", cresta de gallo "planta".

Archimetáfora 14. Un vegetal es otro vegetal

Esta es menos frecuente en sus ocurrencias (3). Se encontró: pepino de mar "planta", uvita de playa "planta", uvita de pájaro "planta".

Archimetáfora 15. Un vegetal es un elemento terrestre

Poco productivo (1). Se encontró chanta piedra "planta".

Archimetáfora 16. Un vegetal es un alimento

Poco productivo (1). Se encontró pan de dios "fruto".

Archimetáfora 17. Una producción de un vegetal es una producción del cuerpo humano

Es poco productivo en nuestro corpus (1): se encontró baba del maíz "líquido que produce el maíz".

Archimetáfora 18. Un objeto es una parte del cuerpo humano

Es frecuente dar nombres de las partes del cuerpo a objetos comunes del entorno (7): lomo del machete "mango, parte del mache que no corta", frente de la casa, "la parte de adelante de la casa", ojo de la cerradura "la parte de la cerradura en donde se coloca la llave", oreja del caldero "la parte del caldero en donde se agarra", oreja del pocillo "parte del pocillo por donde se agarra", culo de botella "la base de la botella", codo de PVC "objeto que sirve como unión de los tubos sanitarios".

Archimetáfora 19. Un objeto es una parte de un animal 
Menos frecuente (1). Se encontró pata de la moto "parte de la moto que sirve como sostén".

\section{Archimetáfora 20. Un objeto es una unidad de medida}

Se utilizan objetos como unidades de medida (2): bola de jabón "un jabón grande en forma circular", una tapa (de limón, de yuca, de coco) "un pedazo".

\section{Archimetáfora 21. Un espacio es una parte del cuerpo humano}

Otras de las características funcionales de cuerpo humano es la ubicación y la deixis. Existen expresiones, locuciones y frases que poseen un sentido espacial en las que interviene una metáfora que tiene como concepto fuente el cuerpo humano (Julia, 2010, p. 117). En el estudio se encontraron partes del cuerpo humano (5) para ubicar personas, animales, plantas u objetos: a la mano "cerca", al pie "cerca, junto al lado de algo o al lado de ellos", a la cabeza "de frente", a dos dedos "cerca", de espalda "sentido contrario".

\section{Archimetáfora 22. Una cualidad inherente es un animal o un vegetal}

Se les da nombre a ciertos animales y plantas por las características físicas y cualidades dadas (5): liso "pez", arrechito6 "pez", puyón "pez”, bonito "pez", mojoso "gusano".

Archimetáfora 23. Una parte del cuerpo humano es una unidad de medida

Partes del cuerpo humano (4) se utilizan como unidades de medida: mano "cinco unidades": una mano de plátano; puñado, puño "medida de una mano": un puñado de arroz; cabeza, cabecita "pedazo": una cabecita de tomate, una cabeza de cebolla; ojo de la ropa "cantidad grande de ropa para lavar".

\section{Archimetáfora 24. Un alimento es una medida}

\footnotetext{
${ }^{6}$ Las actividades humanas nombradas como arrecho y puyón se refieren a tener relaciones
} sexuales constantes. 
Se encontró una (1) metáforas de alimento como unidad de medida: pan de jabón "una barra de jabón".

\section{Archimetáforas 25. Metáforas sinestéticas.}

Estas metáforas están basadas en la transposición de un sentido al otro (4): del oído a la vista, del tacto al oído, etc. Existen expresiones en el habla popular como tener una voz cálida, olores dulces, oler mal una situación, llevar las cosas suaves.

\section{Archimetáforas 26. Metáforas de lo abstracto a lo concreto}

Una de las tendencias básicas de la metáfora consiste en traducir experiencias abstractas en términos concretos (2): el tiempo es arcilla que el hoy moldea a su antojo, significa que el tiempo presente lo manejamos según las circunstancias del hoy; la vida no es tronco de jobo que retoña, indica que cada momento de la vida es único e irrepetible.

\section{Resultados análisis de las archimetáforas}

A continuación se presentan los resultados del total de casos y los porcentajes de las archimetáforas:

\begin{tabular}{|l|l|l|}
\hline Archimetáfora & Casos & Porcentaje \\
\hline 1. El ser humano es un animal & 121 & $6.05 \%$ \\
\hline 2. El ser humano es un vegetal & 31 & $1.55 \%$ \\
\hline $\begin{array}{l}\text { 3. Una parte del cuerpo humano es otra parte del cuerpo } \\
\text { humano }\end{array}$ & 3 & $0.15 \%$ \\
\hline 4.Una parte del cuerpo humano es un objeto & 6 & $0.3 \%$ \\
\hline 5.El ser humano es una enfermedad & 3 & $0.15 \%$ \\
\hline 6. Un animal o una parte de una animal es otro animal & 15 & $0.75 \%$ \\
\hline 7. Un animal es un vegetal & 2 & $0.1 \%$ \\
\hline 8. Un animal es un objeto & 13 & $0.65 \%$ \\
\hline 9. Un animal es un elemento terrestre & 1 & $0.05 \%$ \\
\hline 10.Un vegetal es una parte del cuerpo humano & 4 & $0.2 \%$ \\
\hline
\end{tabular}




\begin{tabular}{|l|l|l|}
\hline 11. Un vegetal es un animal & 22 & $1.1 \%$ \\
\hline 12. Animales transferidos a los alimentos & 1 & $0.05 \%$ \\
\hline 13. Una vegetal es una parte de una animal & 10 & $0.5 \%$ \\
\hline 14. Un vegetal es otro vegetal & 3 & $0.15 \%$ \\
\hline 15. Un vegetal es un elemento terrestre & 1 & $0.05 \%$ \\
\hline 16. Un vegetal es un alimento & 1 & $0.05 \%$ \\
\hline $\begin{array}{l}\text { 17. Una producción de un vegetal es una producción del } \\
\text { cuerpo humano }\end{array}$ & 1 & $0.05 \%$ \\
\hline 18. Un objeto es una parte del cuerpo humano & 7 & $0.35 \%$ \\
\hline 19. Un objeto es una parte de un animal & 1 & $0.05 \%$ \\
\hline 20. Un objeto es una unidad de medida & 2 & $0.1 \%$ \\
\hline 21. Un espacio es una parte del cuerpo humano & 5 & $0.25 \%$ \\
\hline 22. Una cualidad inherente es un animal o un vegetal & 5 & $0.25 \%$ \\
\hline 23. Una parte del cuerpo humano es una unidad de medida & 4 & $0.2 \%$ \\
\hline 24. Un alimento es una medida & 1 & $0.05 \%$ \\
\hline 25. Metáforas sinestésicas & 4 & $0.2 \%$ \\
\hline 26. Metáforas de lo abstracto a lo concreto & 2 & $0.1 \%$ \\
\hline Total & 269 & $13.45 \%$ \\
\hline Tabla 1. Frecuencia de las archimetaforas. & 4 & \\
\hline
\end{tabular}

Tabla 1. Frecuencia de las archimetáforas.

\section{Conclusiones}

De vital importancia son los estudios sobre lingüística cognitiva, antropología cognitiva y de psicología cognitiva para comprender la manera como categorizamos la realidad; las teorías sobre la categorización y la teoría del embodiment, basada en la idea de que la categorización de la realidad está condicionada por la relación del cuerpo con el mundo y en que ello se observa en el lenguaje, permite dar cuenta de la relación que mantienen la mente, el cuerpo y la lengua.

Según los resultados obtenidos en este estudio el cuerpo humano, el mundo animal y vegetal son fuente muy importantes para la categorización de la realidad de las comunidades de los valles de los ríos Sinú y San Jorge. La metáfora, concebida como proceso conceptual, permite mostrar el vínculo que el cuerpo posee con el mundo, así 
como los animales y las plantas. En este estudio la metáfora es el recurso que genera un mayor número de transferencias denominativas entre el cuerpo humano, los animales, y las plantas. Así, el concepto fuente más frecuente en esta investigación es el mundo animal.

Finalmente, se puede afirmar que el estudio del léxico desde la perspectiva de la lingüística cognitiva desde los parámetros de la metáfora conceptual, es uno de los métodos más apropiados para investigar la lengua como reflejo directo de los procesos mentales y el funcionamiento de la categorización de la realidad.

\section{Referencias}

Berlin, B. (1973). Folk systematics in relation to biological classification and nomenclature. Annual Review. Ecol. And Syst. Vol. 4.

Buenafuentes, C. (2003). Procesos de lexicalización en la formación de compuestos sintagmáticos que incluyen una parte del cuerpo. XXXIII Simposio de la Sociedad Española de Lingüística (Universitat de Girona, 16-19 de diciembre de 2003).

Crespillo, J.G. (2011). Enfoque comunicativo y enfoque por tareas en el aprendizaje. Gibralfaro. Revista de Creación Literaria y Humanidades. Publicación Bimestral de Cultura. Año X. II Época. N. 71.

Echevarría, I. (2003). Acerca del vocabulario español de la animalización humana. Círculo de lingüística aplicada a la comunicación, $N^{o} .15$.

Iñesta, E. y Pamies, A. (2002). Fraseología y metáfora. Granada, España: Método.

Jiménez, M. (2013). Metáforas zoonímicas del diccionario de costarriqueñismos de Arturo Agüero Chaves. Káñina, Rev. Artes y Letras, Univ. Costa Rica XXXVII (1): 203-217.

Julià, C. (2010). Estructura y variación en el léxico del cuerpo humano. Tesis doctoral. Universidad Autónoma de Barcelona. Departamento de Filología Española. 
Kekié, K. (2008). El lenguaje figurado con zoonímicos en serbio. Language Design: Metáforas zoonímicas del diccionario de costarriqueñismo. Rev. Artes y Letras, Universidad de Costa Rica XXXVII: 203-217, 2013.

Lakoff G., Johnson M. (1995). Metáforas de la vida cotidiana. Madrid, España: Cátedra.

Ullmann, S. (1980). Semántica. Introducción a la ciencia del significado. Madrid, España: Aguilar. 